\title{
Comprometimento organizacional na comunicação organizacional e relações públicas: uso do conceito em publicações científicas
}

Organizational commitment in organizational communication and public relations: the use of the concept in scientific publications

Compromiso organizacional en comunicación organizacional y relaciones públicas: uso del concepto en publicaciones científicas

\section{(9) Denise Pragana Videira}

- Doutoranda em Ciências da Comunicação pela Escola de Comunicações e Artes da Universidade de São Paulo (ECA-USP).

- Mestra em Ciências da Comunicação pela ECA-USP.

- E-mail: denise.pragana@hotmail.com 


\section{Resumo}

0 artigo examinou em publicações científicas brasileiras da área da comunicação organizacional e de relações públicas se os autores, ao referirem-se ao comprometimento organizacional, usavam conceitos teóricos. Os resultados demonstraram que o comprometimento organizacional vem sendo empregado na área da comunicação com base no senso comum e são poucos os textos que trazem o conceito referendado por teorias. As constatações abrem espaço para que futuras pesquisas proponham bases conceituais do comprometimento organizacional sob o foco da comunicação.

\section{PALAVRAS-CHAVE: RELAÇÕES PÚBLICAS•COMUNICAÇÃOORGANIZACIONAL•COMPROMETIMENTO ORGANIZACIONAL•VÍNCULOS ORGANIZACIONAIS.}

\section{Abstract}

This article investigated the use of theoretical concepts related to organizational commitment by Brazilian researchers of the fields of organization communication and public relations. The results indicate that the communication field has approached the theme of organizational commitment based on common sense, with few articles providing a theoretical framework for the concept. These findings suggest that further research may shed light on the conceptual foundations of organizational commitment under the perspective of communication.

KEYWORDS: PUBLIC RELATIONS • ORGANIZATIONAL COMMUNICATION•ORGANIZATIONAL COMMITMENT • ORGANIZATIONAL ATTACHMENTS.

\section{Resumen}

Este artículo investigó si los autores de publicaciones científicas brasileñas del campo de comunicación organizacional y relaciones públicas, al referirse al compromiso organizacional, utilizaban conceptos teóricos. Los resultados demostraron que el compromiso organizacional viene siendo utilizado en el campo de la comunicación con base en el sentido común y pocos son los textos en que el concepto aparece avalado por teorías. Los hallazgos abren espacio para que futuras investigaciones propongan bases conceptuales del compromiso organizacional bajo el enfoque de la comunicación. 


\section{INTRODUÇÃO}

$\mathrm{D}$ iante da rapidez com que as mudanças têm ocorrido na sociedade, a comunicação passou a ter um papel essencial na gestão dos relacionamentos organizacionais, apontando para uma perspectiva comunicacional relacional, uma vez que a perspectiva transmissiva e instrumental já não é suficiente diante do cenário contemporâneo (Marques; Mafra, 2018). Pesquisadores da corrente crítica da comunicação organizacional e das relações públicas (Holtzhausen, 2016; L'etang, 2004) têm afirmado que nas últimas décadas a comunicação tem servido mais aos interesses das corporações do que da sociedade. Esses estudiosos enfatizam que a produção de narrativas pelos comunicadores é geralmente utilizada para camuflar os interesses corporativos, como defender que o comprometimento organizacional do trabalhador serve para impulsionar os resultados do negócio.

A comunicação organizacional é um processo de construção de sentidos em ambientes de diversidade e de relações conflituosas (Deetz, 2010). Assim, a função do comunicador deve ser de "analista de cenários" (Ferrari, 2011), pois cabe a ele identificar os interesses de todos os envolvidos, não somente da cúpula da organização, e o contexto externo. Quando não há clareza da alta direção sobre a função da comunicação organizacional, as relações de dominação e subordinação no ambiente organizacional tendem a ser assimétricas, podendo trazer efeitos negativos aos relacionamentos e, consequentemente, ao comprometimento das pessoas (Mumby et al., 2017).

Para França (2012), relacionamento é o ato ou efeito de relacionar-se; é a capacidade de conviver com os outros, estabelecer laços oficiais, permanentes ou não, e com objetivos bem definidos. Uma vez que o relacionamento é um vínculo estabelecido entre duas ou mais pessoas e/ou grupos, para que o trabalhador e a empresa permaneçam ligados, é necessário que ambos percebam a existência de um valor comum que reforce a convicção de que vale a pena manter o vínculo afetivo (Ferrari, 2016).

Observando-se a comunicação institucional de algumas organizações brasileiras, é possível verificar que, com a "intenção de manter o trabalhador motivado e comprometido"', muitas vezes são criados dispositivos, como políticas de gestão, recompensas financeiras e campanhas motivacionais. Geralmente, nessas situações, o comunicador atua numa perspectiva transmissiva e instrumental, disseminando tais incentivos em nome do propósito organizacional. No entanto, nem sempre esses dispositivos são eficazes para alcançar o verdadeiro comprometimento do trabalhador com a organização.

Outra forma de comunicação que tenta motivar o empregado para que ele se comprometa afetivamente com a empresa é a produção de slogans e narrativas, tais como: "somos o melhor lugar para construir sua carreira de sucesso" (Banco Bradesco); "lugar de gente feliz" (Grupo Pão de Açúcar); "venha com a gente fazer a diferença" (Gerdau); "aqui encorajamos as pessoas a fazerem a diferença todos os dias, evoluindo e aprendendo sempre" (Braskem); "um time unido pela integridade" (Volkswagen). Esses slogans não são suficientes para envolver afetivamente o empregado e torná-lo comprometido com a organização, principalmente se os dispositivos de comunicação não forem acompanhados de práticas transparentes pela alta administração. Portanto, o comprometimento organizacional depende de outros fatores.

Diante do exposto, os objetivos do artigo são: 1) verificar se os textos de publicações cientificas da área da comunicação organizacional e relações públicas apresentam conceitos sobre comprometimento organizacional; e 2) identificar se os conceitos científicos encontrados pertencem a teorias da área da comunicação organizacional e relações públicas, ou se são de outras áreas do conhecimento. 
A seguir, o artigo traz o referencial teórico dos principais conceitos de comprometimento organizacional e as teorias vigentes, e destaca o processo de comunicação para alcançar o comprometimento organizacional. Na sequência, apresenta os procedimentos metodológicos e os critérios de análise. As seções seguintes trazem as análises dos resultados e as considerações a respeito dos objetivos propostos.

\section{O COMPROMETIMENTO ORGANIZACIONAL E A DIVERSIDADE CONCEITUAL}

Nas últimas décadas do século XX, vários pesquisadores das áreas da psicologia, da sociologia e da administração iniciaram estudos sobre comprometimento organizacional, evidenciando o referido constructo como um dos mais importantes fenômenos psicossociais da área do trabalho e das organizações.

Os estudos sobre comprometimento iniciaram-se nos Estados Unidos, nos campos da psicologia (Lewin, 1952) e da sociologia (Becker, 1960; Kanter, 1968; Ritzer; Trice, 1969). As primeiras referências sobre o constructo encontram-se em língua inglesa, mediante o emprego do termo commitment, traduzido para a língua portuguesa como comprometimento. Nas décadas de 1960 e 1970, o tema passou a interessar pesquisadores do campo das teorias organizacionais, entre os quais destacamos os trabalhos de Etzioni (1961), Meyer e Allen (1984) e Mowday, Steers e Porter (1982).

O comprometimento organizacional foi inicialmente conceituado por Mowday, Steers e Porter (1979) a partir de uma perspectiva unidimensional que enfatizava a natureza afetiva do vínculo, definindo-o como um estado no qual o indivíduo se identifica com uma organização e seus objetivos e deseja manter-se nela.

Meyer e Allen (1991) propuseram um modelo tridimensional desse vínculo, cuja essência está na ideia de que o comprometimento pode ser expresso a partir de três naturezas distintas, representadas por três estados psicológicos ou bases: (i) afetiva, ou o desejo do trabalhador em permanecer e contribuir ativamente para a organização, devido à identificação e ao compartilhamento de valores; (ii) continuação ou instrumental, definido pela noção de permanecer na organização após o cálculo de alternativas, benefícios, investimentos e custos envolvidos no caso de afastamento; e (iii) normativa, cuja origem está na norma de reciprocidade ou sentimento de dever advindo da internalização das normas organizacionais e da necessidade de retribuir o suporte recebido pela organização. Meyer e Allen (1991) reforçaram que os indivíduos comprometidos afetivamente permanecem na organização porque desejam, enquanto os indivíduos comprometidos instrumentalmente continuam porque precisam e os comprometidos normativamente permanecem uma vez que se sentem em débito com ela.

Os primeiros estudos sobre comprometimento surgiram no Brasil com Bastos (1992, 1993), que passou a ser referência indispensável da área. Além do conceito do comprometimento de base afetiva, dois novos conceitos foram propostos: o entrincheiramento organizacional (Rodrigues, 2009) e o consentimento organizacional (Silva, 2009).

0 conceito de entrincheiramento foi proposto por Rodrigues (2009) como a tendência do indivíduo de permanecer na organização devido às perdas associadas a sua saída, como benefícios, vantagens financeiras, investimentos no ajustamento ao cargo, redes de contatos, entre outras que restringem a percepção de alternativas de emprego que as supram (Rodrigues; Bastos, 2011). Já o conceito de consentimento organizacional é compreendido como a tendência do trabalhador a obedecer às demandas da empresa, personificadas por seus superiores. Silva e Bastos (2015) defendem que o cumprimento das ordens e normas por parte do trabalhador ocorre devido às relações de poder e autoridade que se estabelecem entre subordinado e superior, bem como por ele acreditar que a chefia sabe melhor o que deve ser feito. 
As novas propostas dos pesquisadores brasileiros a respeito das inconsistências empíricas do modelo tridimensional de Meyer e Allen (1991) podem ser observadas na Figural. Dessa forma, o vínculo do comprometimento organizacional foi delimitado como sendo apenas o de base afetiva e dois novos vínculos são acrescentados: 0 entrincheiramento organizacional, em substituição à base de continuação, e o consentimento organizacional, em substituição à base normativa.

Figural: Definições de comprometimento, entrincheiramento e consentimento na organização

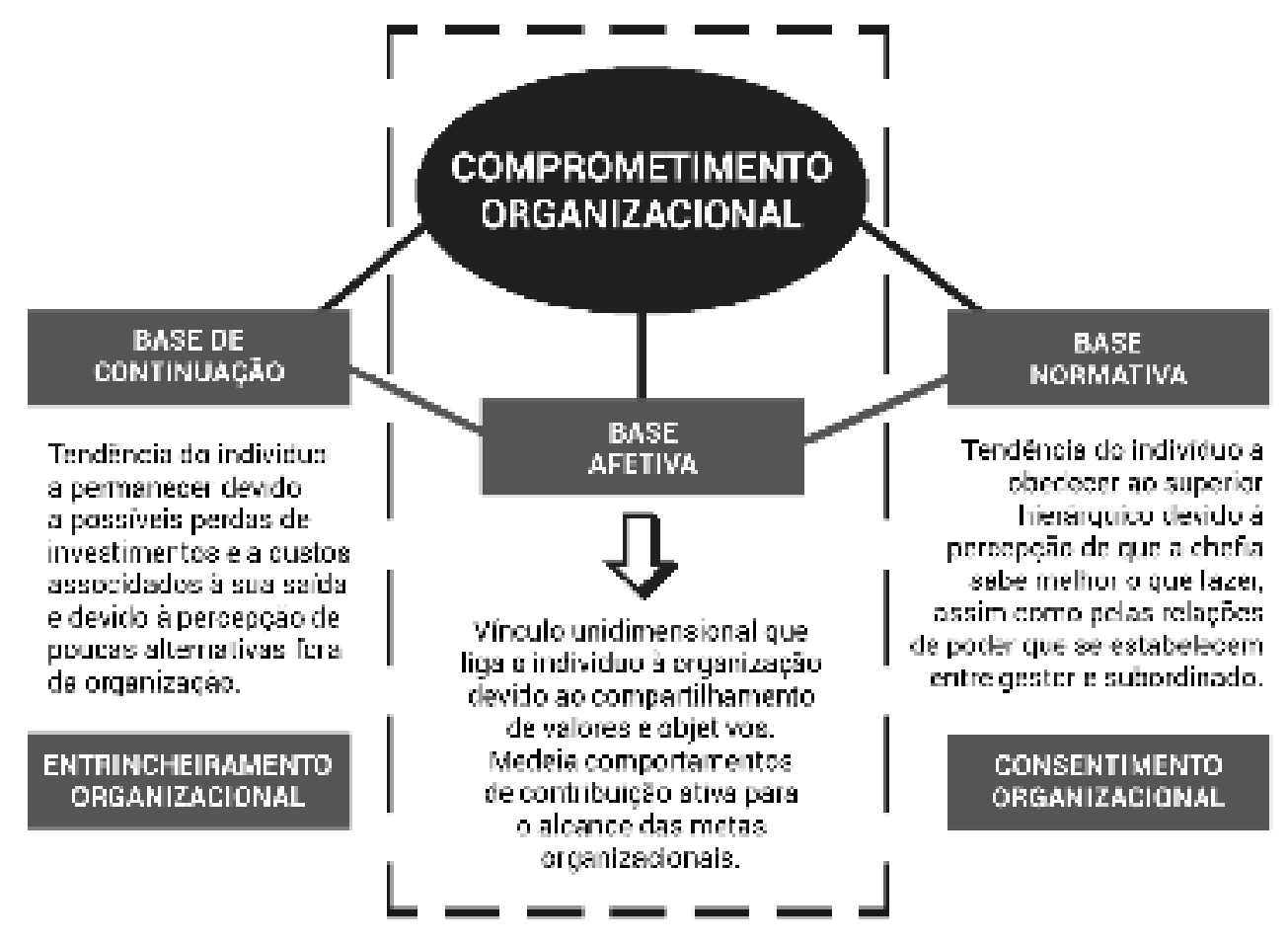

Fonte: Bastos et al. (2013, p.287).

A Figura 1 reforça a proposta de Rodrigues (2009) que apresenta o conceito de entrincheiramento como resposta às inconsistências observadas quanto à base instrumental ou ao comprometimento de continuação (Meyer; Allen, 1991). Na sequência, Silva $(2009,2013)$ contribuiu com o conceito de consentimento, que surgiu na literatura da sociologia do trabalho e caracteriza-se por um tipo de vínculo do indivíduo pautado na internalização do papel de subordinação existente nas relações de trabalho, o que o leva a consentir ou a obedecer às normas e às regras da organização, comumente proferidas pelo superior imediato.

\section{O CONCEITO DE COMPROMETIMENTO ORGANIZACIONAL SOB A ÓTICA DA COMUNICAÇÃO ORGANIZACIONAL E DAS RELAÇÕES PÚBLICAS}

No mundo contemporâneo do trabalho, a comunicação nas organizações é complexa e diz respeito às relações e ao comportamento. Wolton (2011, p. 26) completa afirmando que "a comunicação é associada à ideia de vínculo, de compartilhamento e de 'comunhão'".

A expressão "comprometimento organizacional" é usada frequentemente na bibliografia especializada. Autores mencionam que as ações de comunicação organizacional e de relações públicas têm como finalidade o "comprometimento dos indivíduos com a organização" (Bueno, 2013; Fossá, 2014; França, 2011; Grunig; Ferrari; França, 2011; Oliveira; Nader, 2017). Os textos relacionam o comprometimento organizacional com a satisfação e a permanência do indivíduo na organização para referendar o êxito de campanhas comunicacionais, à medida que significa o cumprimento de metas e objetivos organizacionais. 
Assim, é importante reforçar a definição de Bastos et al. (2013, p.287), com base em dados de Rodrigues (2009) e Silva (2009), que afirmam ser o comprometimento "um vínculo que liga o indivíduo à organização devido ao compartilhamento de valores e objetivos".

Se nas áreas da psicologia, da administração e da sociologia o conceito de comprometimento tem respaldo em teorias de autores internacionais e brasileiros, encontramos na área de relações públicas a pesquisa realizada por Linda Hon e James Grunig (1999) que, pela primeira vez, apresentaram bases teóricas para explicar o fenômeno do comprometimento organizacional. 0 estudo demonstra que é possível medir a qualidade dos relacionamentos com base em quatro indicadores: reciprocidade de controle, confiança, satisfação e comprometimento. Para os autores, o comprometimento é "a medida na qual cada uma das partes sente ou não que o relacionamento vale o dispêndio de energia para mantê-lo ou promovê-lo" (Hon; Grunig, 1999, p.3). Para eles, conforme o comunicador estabelece as bases dos relacionamentos corporativos, os indicadores são considerados medidas para avaliar os resultados das relações estabelecidas. Os indicadores de qualidade dos relacionamentos podem ser utilizados não somente como mensuração do quanto as pessoas estão cooperando para atingir as metas organizacionais, mas também para verificar se elas estão se vinculando afetivamente aos valores da empresa.

Uma das finalidades da manutenção de relacionamentos positivos entre públicos e organizações é alcançar o vínculo do comprometimento. Segundo Rodrigues e Bastos (2011), as organizações dependem essencialmente da presença, articulação, vinculação, afeto e comprometimento dos trabalhadores para conseguir seus objetivos e propósitos organizacionais.

Por outro lado, ao relacionar o comprometimento organizacional com a área da comunicação organizacional e de relações públicas, é necessário lembrar que a comunicação, sendo uma atividade "meio", tem como uma de suas finalidades analisar cenários (Ferrari, 2011) e, em seguida, estabelecer estratégias de ação a fim de proporcionar bem-estar aos indivíduos para então atingir os objetivos das organizações. Desta forma, se alcançaria a função do "comunicador ativista" (Holtzhausen, 2016), cuja missão vai além das práticas instrumentais, adquirindo a perspectiva relacional (Marques; Mafra, 2018), que permite ao comunicador colaborar com a resolução de conflitos e dilemas que ocorrem cotidianamente entre líderes e liderados nas organizações.

\section{PROCEDIMENTOS METODOLÓGICOS}

Este artigo traz o resultado de um estudo reflexivo, descritivo e exploratório. Após a revisão da literatura sobre comprometimento e comunicação, foram analisadas teses e dissertações do catálogo da Coordenação de Aperfeiçoamento de Pessoal de Nível Superior (Capes), entre 2013 e 2018', e artigos publicados na revista Organicom - periódico especializado em comunicação organizacional e relações públicas - desde sua criação, em 2004, até 2018.

Foram definidos os seguintes critérios para o catálogo da Capes: 1) presença do termo "comprometimento"; 2) aplicação do filtro para trabalhos produzidos no âmbito das ciências sociais aplicadas; 3) delimitação da comunicação como área de conhecimento. 0 período definido a partir de 2013 se deve ao início da digitalização dos trabalhos na plataforma institucional. Foram encontrados 18 trabalhos.

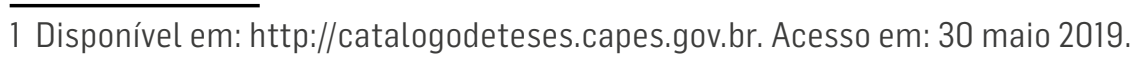


Para a Organicom, utilizou-se apenas a busca do termo "comprometimento" em 29 edições, uma vez que o periódico pertence às áreas especificas de comunicação organizacional e relações públicas. Foram encontrados 77 textos, entre eles um depoimento, quatro entrevistas, quatro resenhas e 68 artigos. Para fins desse estudo, analisamos apenas os 68 artigos.

Os documentos selecionados (teses, dissertações e artigos) foram analisados em quatro etapas: a) leitura dos títulos; b) resumo; c) palavras-chave; e d) leitura do texto completo. Esse método permitiu verificar a linha de pesquisa, o objetivo de cada texto e como o termo comprometimento era tratado.

Foram criadas três categorias de análise dos textos: (i) comprometimento como palavra polissêmica de uso corrente (no sentido de: compromisso, prejuízo, esforço, lealdade a algo, responsabilidade e valor); (ii) comprometimento organizacional mencionado como "vínculo organizacional", sem citação de conceitos e autores; (iii) comprometimento organizacional como "vínculo organizacional" baseado em definições e autores referenciais.

\section{ANÁLISE DOS RESULTADOS}

No catálogo da Capes, foram encontrados 18 documentos - cinco teses e 13 dissertações - (Tabela 1) que obedeciam aos critérios definidos, englobando as áreas da comunicação organizacional, do jornalismo, da publicidade e da semiótica. Somente Amaral (2018) empregou o comprometimento no sentido de vínculo organizacional em interface com a comunicação usando teorias e autores para justificar o conceito. 0 termo comprometimento organizacional constava no título e nas palavras-chave. Trata-se de uma tese de doutorado de 2018 sobre as interfaces entre comunicação e comprometimento organizacional no âmbito de cooperativas, que demonstrou bons níveis de comprometimento afetivo em quatro cooperativas analisadas.

Tabela 1: Análise do catálogo de teses e dissertações da Capes

\begin{tabular}{l|c|c}
\multicolumn{1}{c|}{ Emprego do termo comprometimento } & $\begin{array}{c}\text { Quantidade de textos } \\
\text { selecionados }\end{array}$ & $\%$ \\
\hline $\begin{array}{l}\text { Como vínculo organizacional-com base científica do campo da administração } \\
\text { e/ou relações públicas. }\end{array}$ & 1 & $5,5 \%$ \\
\hline $\begin{array}{l}\text { Como vínculo organizacional - sem base científica e sem menção de } \\
\text { conceitos e teorias. }\end{array}$ & 0 & $0 \%$ \\
\hline Como sentido polissêmico - uso corrente do termo comprometimento. & 17 & $94,4 \%$ \\
\hline Total dos trabalhos analisados & 18 & $100 \%$ \\
\hline
\end{tabular}

Fonte: Elaborada pela autora.

Nos demais trabalhos, a palavra comprometimento aparecia em diversas formas de uso corrente do termo, e não como vínculo com a organização. Na linguagem cotidiana, comprometimento pode significar compromisso em relação a um determinado alvo, ou seja, o grau de atenção, de esforço e cuidado que a pessoa destina ao realizar algo ou um estado de lealdade a algo, podendo também referir-se a produtos indesejados, por exemplo, comprometer no sentido de prejudicar ou impedir (Bastos, 1994).

Foram analisadas as 29 edições da revista Organicom, publicadas entre 2004 e 2018. Dos 68 artigos selecionados, constatou-se que apenas quatro (5,9\%) referendavam o comprometimento organizacional por meio de conceito científico, seja como vínculo organizacional, a partir de referências dos autores do campo da administração e da psicologia, 
como Meyer e Allen (1991) e Bastos et al. (2013), seja como um dos fatores do relacionamento organizacional com base em autores do campo da comunicação organizacional e de relações públicas (Hon; Grunig, 1999). A Tabela2 apresenta a análise dos artigos selecionados na revista Organicom.

Tabela 2: Análise dos artigos selecionados da revista Organicom

\begin{tabular}{l|c|c}
\hline \multicolumn{1}{c|}{ Emprego do termo comprometimento } & $\begin{array}{c}\text { Quantidade de textos } \\
\text { selecionados }\end{array}$ & $\%$ \\
\hline $\begin{array}{l}\text { Como vínculo organizacional - com base científica do campo da administração } \\
\text { e/ou relações públicas. }\end{array}$ & 4 & $5,9 \%$ \\
\hline $\begin{array}{l}\text { Como vínculo organizacional - sem base científica e sem menção de conceitos } \\
\text { e teorias. }\end{array}$ & 8 & $11,8 \%$ \\
\hline Como sentido polissêmico - uso corrente do termo comprometimento. & 56 & $82,3 \%$ \\
\hline Total dos artigos analisados & 68 & $100 \%$ \\
\hline
\end{tabular}

Fonte: Elaborada pela autora.

Os temas abordados pelos quatro artigos que apresentaram o comprometimento organizacional com base científica variaram entre (i) mensuração da eficácia das relações públicas; (ii) análise de escala de relacionamento organizacional; (iii) gestão do relacionamento líderes-liderados; e (iv) apresentação de pesquisa sobre a relação entre informação, comunicação e comprometimento organizacional para o engajamento dos funcionários nos projetos de responsabilidade social. Apenas o último incluiu o termo comprometimento tanto no título como nas palavras-chave.

Três desses artigos basearam-se no conceito de comprometimento como um dos quatro indicadores de relacionamentos organizacionais com seus públicos, propostos por Hon e Grunig (1999). Entre esses está o artigo de Linda Hon (2005), cujo objetivo foi discutir sobre a diversidade de indicadores empregados na mensuração da eficácia das práticas das relações públicas. Nele, o comprometimento surge como um dos indicadores da qualidade dos relacionamentos. Vale destacar que Linda Hon (2005) também citou Meyer e Allen (1984) como referências clássicas sobre o conceito de comprometimento, explicando o fenômeno como uma conexão emocional entre a organização e seu público.

Bonfadini e Kirst (2007) analisaram a construção e a validação de uma escala de relacionamento organizacional, proposta por Bonfadini (2007). A escala, denominada integrativa, é do tipo multi-itens, formada pelos constructos comprometimento, confiança, cooperação, poder e satisfação. Segundo Hon e Grunig (1999), o comprometimento é a medida por meio da qual as partes acreditam que vale a pena gastar energia para manter e expandir o relacionamento, e apresenta duas dimensões: comprometimento contínuo, relativo a uma determinada linha de conduta, e comprometimento afetivo, derivado de uma orientação emocional.

0 artigo de Lima (2010) abordou a importância e a gestão dos relacionamentos por meio da comunicação dirigida para os resultados da ouvidoria. 0 autor cita o trabalho de Bonfadini (2006) que, por sua vez, segue a definição de Hon e Grunig (1999) para o comprometimento como um dos indicadores de relacionamento de longo prazo.

O quarto artigo, além de conceituar o comprometimento organizacional, incluiu o termo no título e nas palavras-chave. Fachinelli etal. (2013) realizaram uma pesquisa interna para estudar a relação da informação e da comunicação com o comprometimento, considerado suporte para o engajamento dos funcionários das empresas em seus projetos de responsabilidade social. As autoras incluem 0 comprometimento como um dos temas cada vez mais presentes nas organizações, uma vez que está associado a diferenciais competitivos e fazem referência a Bastos (1994), um dos principais teóricos do fenômeno do comprometimento organizacional no Brasil. 
Os oito artigos selecionados na categoria vínculo organizacional sem base científica do campo da administração e/ou das relações públicas discutiram a contribuição da comunicação na geração do comprometimento de funcionários com a organização, sem apresentar, porém, definição do constructo comprometimento ou referencial teórico que pudesse embasar o emprego do termo.

Neste grupo, destacamos dois trechos que mostram como o termo comprometimento foi utilizado e não definido:

Observamos que a obtenção da participação foi uma tônica do projeto, com a conquista do comprometimento de várias áreas e níveis da organização. Estes aspectos reforçam a importância da participação das pessoas como sujeitos (participantes ativos) e não como objetos (passivos) no processo de construção do futuro, o que vinculamos ao modelo de comunicação baseado nos estudos culturais. (Felisbino, 2004, p.105)

A palavra comprometimento foi mencionada no artigo de várias formas: 1) com o sentido de vínculo dos funcionários com os objetivos organizacionais; 2) no sentido de compromisso com o processo de mudança; 3) emprego do compromisso da liderança como indicador de sucesso do projeto; 4) no sentido de compromisso dos parceiros como indicador do sucesso do projeto. Porém, em nenhum momento são encontradas definições ou embasamentos para sustentar tais empregos.

Em outro texto, destaca-se a frase: "Os jovens têm sinalizado para a importância de duas posturas novas a serem observadas na administração moderna: a flexibilidade organizacional e a descentralização do poder [...] pois criam condições para o efetivo comprometimento dos públicos internos" (Bueno, 2013, p.67). Esse trecho faz parte de um artigo teórico que busca evidenciar a necessidade de mudanças importantes no modelo de gestão e nas posturas dos gestores das organizações brasileiras, em particular nos processos, ações e estratégias de comunicação que caracterizam a comunicação interna. Propõe a introdução do sistema de liderança aberta para garantir o efetivo comprometimento dos funcionários, a fim de favorecer a construção de um clima organizacional saudável e reter os verdadeiros talentos das organizações. 0 artigo refere-se ao comprometimento dos funcionários da geração Y no sentido de vínculo com a organização, porém não trabalha com conceitos ou constructos para definir o que o comprometimento organizacional significa.

Os demais 56 artigos empregaram a palavra comprometimento em seu uso corrente, com os significados de compromisso, caráter, identificação, valor, obrigação, responsabilidade etc., em diversos contextos - governança, mudança cultural, responsabilidade social, gestão de crise, entre outros.

\section{DISCUSSÃO}

Como apresentado no capítulo introdutório, o primeiro objetivo foi verificar se os textos analisados apresentavam conceitos sobre comprometimento. De acordo com o levantamento realizado, foram ínfimos os trabalhos que empregaram o termo comprometimento organizacional no sentido de vínculo organizacional e baseado em teorias. 0 fato de só ter sido encontrada uma tese de doutorado e apenas quatro artigos publicados na revista Organicom em conformidade com os critérios definidos pela pesquisa e que mencionam o comprometimento organizacional mediante conceitos referendados, em um total de 86 achados, mostra a fragilidade da área de comunicação organizacional e relações públicas em não empregar conceitos sobre o comprometimento organizacional, pelo menos na amostra pesquisada.

O segundo objetivo foi identificar se os conceitos científicos encontrados pertenciam a teorias da área da comunicação organizacional e relações públicas, ou se eram de outras áreas do conhecimento. Mesmo diante da pequena quantidade de trabalhos encontrados, foi possível perceber o ganho científico advindo dos conceitos da administração, da psicologia social e das relações públicas nos cinco trabalhos que empregaram tais conceitos. Por outro lado, constatamos que os autores dos 
oito textos que mencionam o comprometimento organizacional como parâmetro para demonstrar o papel estratégico dos processos comunicacionais, mas sem nenhuma base conceitual, poderiam ter enriquecido tal demonstração ao identificar as bases conceituais empregadas para definir o comprometimento organizacional.

Este artigo se baseou unicamente na análise dos textos pesquisados. Assim, lança-se a suposição de que tanto a comunicação organizacional quanto as relações públicas, como subárea da comunicação (França; Ferrari, 2007), apresentam lacunas epistemológicas e conceituais que devem ser transpostas, pois a falta de referenciais teóricos na produção científica de um determinado campo (e subcampo) de estudo pode ocasionar sua fragilidade científica.

\section{CONSIDERAÇÕES FINAIS}

0 artigo buscou reforçar a importância do comprometimento organizacional como um vínculo afetivo que tem papel vital para a manutenção de relacionamentos saudáveis, verdadeiros e permanentes. Da mesma forma como outras áreas do conhecimento já utilizam o comprometimento para avaliar as performances dos trabalhadores nas organizações, a área de comunicação organizacional e de relações públicas precisa compreender que não será somente no uso de dispositivos e ações comunicacionais sazonais que a organização alcançará o comprometimento organizacional de seus trabalhadores. Para essa conquista, é necessário que todos os níveis hierárquicos interajam, pois só assim é possível praticar o propósito organizacional; como resultado, será possível dar sentido à existência de um valor comum que reforce a convicção de que vale a pena manter o vínculo afetivo com a organização.

Atuando como meio, a função da comunicação é proporcionar significado aos colaboradores sobre as ações organizacionais, mas desde que sejam encontrados caminhos que mostrem essa contribuição de forma estruturada e cientificamente embasada.

Tais constatações colocam em discussão a precariedade teórica do campo da comunicação organizacional e relações públicas, especificamente em relação ao tema do comprometimento organizacional, mas também oferecem oportunidades para o desenvolvimento de pesquisas que abordem a interface da comunicação com os vínculos organizacionais, sejam eles o comprometimento, o consentimento ou o entrincheiramento. A nova lógica da comunicação deve ter o comprometimento organizacional como um vínculo a serviço das liberdades individuais, respeitando valores e significados do sujeito e não como uma estratégia articulada pela alta direção das organizações somente para atingir seus objetivos de negócio.

Os desafios que cercam as relações de trabalho são diversos, principalmente nos países latino-americanos que têm vivido tempos de crise de confiança institucional e corporativa nos últimos anos. Assim, cresce a importância de se buscar clareza sobre como se estabelecem os vínculos organizacionais e como a comunicação pode influenciá-los, especialmente em relação à busca pela construção de relações de confiança entre trabalhadores e suas organizações empregadoras.

\section{REFERÊNCIAS}

AMARAL, Maura Padula de Sousa. Interfaces entre comunicação, cultura e comprometimento no fortalecimento do capital social em cooperativas: estudo múltiplo de casos. 2018. Tese (Doutorado em Interfaces Sociais da Comunicação) Universidade de São Paulo, São Paulo, 2018. 
BASTOS, Antonio Virgílio Bitencourt; RODRIGUES, Ana Carolina de Aguiar; MOSCON, Daniela Campos Bahia; SILVA, Eliana Edington da Costa; PINHO, Ana Paula Moreno. Comprometimento no trabalho: fundamentos para a gestão de pessoas. In: BORGES, Livia de Oliveira; MOURÃO, Luciana (org.). O trabalho e as organizações. atuações a partir da psicologia. Porto Alegre: Artmed, 2013. p.279-310.

BASTOS, Antonio Virgílio Bittencourt. Comprometimento no trabalho: a estrutura dos vínculos do trabalho com a organização, a carreira e o sindicato. 1994. Tese (Doutorado em Psicologia) - Universidade de Brasília, Brasília, DF, 1994.

BASTOS, Antonio Virgílio Bittencourt. Comprometimento organizacional: um balanço dos resultados e desafios que cercam essa tradição de pesquisa. Revista de Administração de empresas, São Paulo, v.33, n. 3, p.52-64, 1993. doi: https://doi.org/10.1590/S0034-75901993000300005.

BASTOS, Antonio Virgílio Bittencourt. Os vínculos indivíduo-organização: uma revisão da pesquisa sobre comprometimento organizacional. In: ENCONTRO ANUAL DA ANPAD, 16., 1992, Canela. Anais [...]. Porto Alegre: Anpad, 1992. p.290-304.

BECKER, Howard S. Notes on the concept of commitment. American Journal of Sociology, Chicago, v.66, n.1, p.32-40, 1960.

BONFADINI, Gerson José. O relacionamento com públicos como estratégia de comunicação nas organizações. 2007. Tese (Doutorado em Comunicação Social) - Pontifícia Universidade Católica do Rio Grande do Sul, Porto Alegre, 2007.

BONFADINI, Gerson José. O relacionamento das organizações com públicos: uma abordagem comparativa entre as relações públicas e o marketing de relacionamento. UNIrevista, São Leopoldo, v.1, n.3, 2006.

BONFADINI, Gerson José; KIRST, Sandro Luis. A mensuração do relacionamento organizacional: construção e validação de uma escala oriunda de duas áreas do conhecimento humano. Organicom, São Paulo, v. 4, n. 7, p.178-197, 2007. doi: https://doi.org/10.11606/issn.2238-2593.organicom.2007.138951.

BUENO, Wilson da Costa. Comunicação interna e liderança aberta: os desafios de incorporar a geração Y e as mídias sociais. Organicom, São Paulo, v.10, n.19, p.60-71, 2013. doi: https://doi.org/10.11606/issn.2238-2593.organicom.2013.139192.

DEETZ, Stanley. Comunicação organizacional: fundamentos e desafios. In: MARCHIORI, Marlene (ed.). Comunicação e organização: reflexões, processos e práticas. São Caetano do Sul: Difusão, 2010. p.83-101.

ETZIONI, Amitai. A comparative analysis of complex organizations: on power, involvement, and their correlates. New York: Free Press of Glencoe, 1961.

FACHINELLI, Ana Cristina; RECH, Jane; GIACOMELO, Cintia Paese; BRANDT, Grazielle Betina; MANOZZO, Mariana Tiburi. Informação, comunicação e comprometimento: um desafio para o engajamento do público interno. Organicom, São Paulo, v.10, n.19, p.170-183, 2013. https://doi.org/10.11606/issn.2238-2593.organicom.2013.139202.

FELISBINO, Patricia. Comunicação e gestão de mudanças: estudo de caso em uma indústria química. Organicom, São Paulo, v.1, n.1, p.99-105, 2004. doi: https://doi.org/10.11606/issn.2238-2593.organicom.2004.138872.

FERRARI, Maria Aparecida. Os cenários turbulentos como oportunidade de mudança e de realinhamento de estratégias. In: GRUNIG, James E.; FERRARI, Maria Aparecida; FRANÇA. Fábio. Relações públicas: teoria, contexto e relacionamentos. São Caetano do Sul: Difusão, 2011, p.137-166. 
FERRARI, Maria Aparecida. Relacionamiento: la clave para el diálogo corporativo. In: ROMERO-RODRIGUEZ, Luis Miguel; CHÁVEZ, Rosalina Mancinas (ed.). Comunicación institucional y cambio social. Sevilla: Egregius, 2016. p.65-82.

FOSSÁ, Maria Ivete Trevison. Possibilidades de análise da diversidade cultural pelas instâncias mítica, socialhistórica, institucional, organizacional, grupal, individual e pulsional. Organicom, São Paulo, v.11, n. 21, p. 123-132, 2014. doi: https://doi.org//10.11606/issn.2238-2593.organicom.2014.139245.

FRANÇA, Fábio. Públicos: como identificá-los em nova visão estratégica. São Paulo: Yendis, 2012.

FRANÇA, Fábio. Relacionamentos corporativos. In: GRUNIG, James E.; FERRARI, Maria Aparecida; FRANÇA, Fábio. Relações públicas: teoria, contexto e relacionamentos. São Caetano do Sul: Difusão, 2011. p.209-271.

FRANÇA, Fábio; FERRARI, Maria Aparecida. Reflexões sobre uma nova proposta de classificação da comunicação e de suas áreas. In: CONGRESSO BRASILEIRO DE CIÊNCIAS DA COMUNICAÇÃO, 30., 2007, Santos. Anais [...]. Santos: Intercom, 2007.

GRUNIG, James E.; FERRARI, Maria Aparecida; FRANÇA, Fábio. Relações públicas: teoria, contexto e relacionamentos. São Caetano do Sul: Difusão, 2011.

HOLTZHAUSEN, Denira. Las relaciones públicas como activismo. Barcelona: UOC, 2016.

HON, Linda Childers. 0 mosaico da avaliação em relações públicas. Organicom, São Paulo, v. 2, n. 2, p.96-115, 2005. doi: https://doi.org/10.11606/issn.2238-2593.organicom.2005.138883.

HON, Linda Childers; GRUNIG, James E. Guidelines for measuring relationships in public relations. Gainesville: Institute for Public Relations, 1999.

KANTER, Rosabeth Moss. Commitment and social organization: a study of commitment mechanisms in utopian communities. American sociological review, Chicago, v.33, n.4, p.499-517, 1968. doi: https://doi.org/10.2307/2092438.

LEWIN, Kurt. Group decision and social change. Im: NEWEOMB, Theodore M.; HARTLEY, Eugene L. (ed.). Readings in social psychology. New York: Holt, 1952. p.197-211.

LIMA, Chulessy Souza. Gestão de relacionamento com líderes: desafio para o ouvidor. Organicom, São Paulo, v.7, n.12, p.150-165, 2010. doi: https://doi.org/10.11606/issn.2238-2593.organicom.2010.139053.

MARQUES, Ângela; MAFRA, Renan. A comunicação interna em contextos organizacionais e a criação de cenas de dissenso. Revista Comunicação Pública, Marseille, v.13, n.25, p.1-31, 2018. doi: https://doi.org/10.4000/cp.2940.

MEYER, John P.; ALLEN, Natalie J. A three-component conceptualization of organizational commitment. Human Resource Management Review, Amsterdam, v.1, n.1, p.61-89, 1991. doi: https://doi.org/10.1016/1053-4822(91)90011-Z.

MEYER, John P.; ALLEN, Natalie J. Testing the "side-bet theory" of organizational commitment: some methodological considerations. Journal of applied psychology, Washington, DC, v.69, n.3, p.372-378, 1984. doi: https://doi.org/10.1037//0021-9010.69.3.372. 
MOWDAY, Richard T.; STEERS, Richard M.; PORTER, Lyman W. Employee turnover and post decision accommodation processes. Eugene: University of Oregon, 1979.

MOWDAY, Richard T.; STEERS, Richard M.; PORTER, Lyman W. Employee-organization linkages: the psychology of commitment, absenteeism, and turnover. New York: Academic Press, 1982.

MUMBY, Dennis K.; THOMAS, Robyn; MARTÍ, Ignasi; SEIDL, David. Resistance redux. Organization Studies, Thousand Oaks, v.38, n.9, p.1157-1183, 2017. doi: https://doi.org/10.1177/0170840617717554.

OLIVEIRA, Maria José da Costa; NADER, Silvana Maria. Empreendedorismo social na interface entre comunicação pública e capital social. Organicom, São Paulo, v.14, n.26, p.41-51, 2017. doi: https://doi.org/10.11606/issn.2238-2593. organicom.2017.139355.

RITZER, George; TRICE, Harrison M. An empirical study of Howard Becker's side-bet theory. Social forces, Ann Arbor, v.47, n.4, p.475-479, 1969. doi: https://doi.org/10.2307/2574537.

RODRIGUES, Ana Carolina de Aguiar. Do comprometimento de continuação ao entrincheiramento organizacional: o percurso de validação da escala e análise de sobreposição entre os construtos. 2009. Dissertação (Mestrado em Psicologia) Universidade Federal da Bahia, Salvador, 2009.

RODRIGUES, Ana Carolina de Aguiar; BASTOS, Antonio Virgílio Bittencourt. Entrincheiramento organizacional: proposta de um novo vínculo indivíduo-organização. In: ZANELLI, José Carlos; SILVA, Narbal; TOLFO, Suzana da Rosa (ed.). Processos psicossociais nas organizações e no trabalho. São Paulo: Casa do Psicólogo, 2011. p.161-178.

SILVA, Eliana Edington da Costa. Consentimento organizacional: uma proposta de medida do construto. 2009. Dissertação (Mestrado em Psicologia) - Universidade Federal da Bahia, Salvador, 2009.

SILVA, Eliana Edington da Costa. Consentimento ou comprometimento? Delimitação conceitual e empírica dos vínculos do indivíduo com a organização. 2013. Tese (Doutorado em Psicologia) - Universidade Federal da Bahia, Salvador, 2013.

SILVA, Eliana Edington da Costa; BASTOS, Antonio Virgílio Bittencourt. Consentimento organizacional. In: PUENTE-PALACIOS, Katia; PEIXOTO, Adriano de Lemos Alves (org.). Ferramentas de diagnóstico para organizações e trabalho: um olhar a partir da psicologia. Porto Alegre: Artmed, 2015. p.92-106.

WOLTON, Dominique. Informar não é comunicar. Porto Alegre: Sulina, 2011.

Artigo recebido em 15.07.2021 e aprovado em 27.09.2021. 